\title{
Conceito e modelos de 'knowledge translation' na área de saúde
} Concept and models of 'knowledge translation' in the health area

\section{Concepto y modelos de 'knowledge translation' en el área de salud}

\author{
Martha Silvia Martínez-Silveira ${ }^{1, a}$ \\ martha.silveira@gmail.com | http://orcid.org/0000-0002-1004-1784
}

Cícera Henrique da Silva ${ }^{2, b}$

cicera.henrique@icict.fiocruz.br | http://orcid.org/0000-0002-3298-795X

Josué Laguardia ${ }^{2, c}$

josue.laguardia@icict.fiocruz.br | https://orcid.org/0000-0003-1456-5590

${ }^{1}$ Fundação Oswaldo Cruz, Instituto Gonçalo Moniz. Salvador, BA, Brasil.

${ }^{2}$ Fundação Oswaldo Cruz, Instituto de Comunicação e Informação Científica e Tecnológica em Saúde. Rio de Janeiro, RJ, Brasil.

a Doutorado em Ciências pela Fundação Oswaldo Cruz.

${ }^{\text {b }}$ Doutorado em Ciências da Informação e da Comunicação pela Université d'Aix-Marseille III.

' Doutorado em Saúde Pública pela Fundação Oswaldo Cruz.

\section{Resumo}

O uso dos resultados da pesquisa e do conhecimento bem como a aplicação das descobertas científicas no mundo real não ocorrem de forma natural. Instituições acadêmicas e governos têm definido que a translação da pesquisa é uma prioridade para a saúde: as evidências científicas devem embasar as decisões para melhorar a saúde. Porém, a lacuna entre ciência e prática, os entraves naturais e criados entre elas mostram que a translação do conhecimento é um processo que precisa ser implementado. As formas de fazê-lo requerem atitudes do meio acadêmico e do ambiente político e de gestão, algo complexo e de difícil solução. Este artigo busca compreender o tema por meio da leitura de autores da área de saúde. Detémse com especial atenção na conceituação e nos modelos disponíveis, além de analisar como se dá essa passagem de evidências entre o campo da ciência e os responsáveis pelas tomadas de decisão e como estas são utilizadas.

Palavras-chave: Transferência de conhecimento; Acesso à informação; Translação do conhecimento; Ciência; Aplicação de descobertas científicas; Decisões em saúde. 


\section{Abstract}

The use of research results and knowledge as well as the application of scientific discoveries in the real world do not occur naturally. Academic institutions and governments have defined that the research translation is a priority for health: decisions should be based on scientific evidence to improve health. However, the gap between science and practice, the natural and created barriers between them show that the knowledge translation is a process that has to be implemented. The ways to do it involve attitudes in both academic, managerial and political environment, which are a issue quite complex and difficult to solve. This paper proposes to understand the topic by reading some authors of the health field. We give a special attention to the concepts, the available models and we analyze how the exchange of evidence between science and decision makers takes place and how the evidence is used.

Keywords: Knowledge transfer; Access to information; Knowledge translation; Science; Application of scientific findings; Health decisions.

\section{Resumen}

El uso de los resultados de la investigación y el conocimiento, así como la aplicación de descubrimientos científicos en el mundo real, no ocurren naturalmente. Instituciones académicas y gobiernos han definido que la traslación de la investigación es una prioridad para la salud: las evidencias científicas deben respaldar las decisiones para mejorar la salud. Sin embargo, el intervalo entre ciencia y práctica, los obstáculos naturales y creados entre ellas muestran que la traslación del conocimiento es un proceso que necesita ser implementado. Las formas de hacerlo implican actitudes del medio académico y del ambiente político y de gestión, algo complejo y de difícil solución. Este artículo propone entender el tema por medio de la lectura de autores del área de salud. Nos detenemos en la conceptualización, los modelos, y analizamos la manera de intercambiar evidencias entre el campo de la ciencia y los responsables de la toma de decisiones y el modo como estas son usadas.

Palabras clave: Transferencia de conocimiento; Acceso a la información; Traslación del conocimiento; Ciencia; Aplicación de descubrimientos científicos; Decisiones en salud.

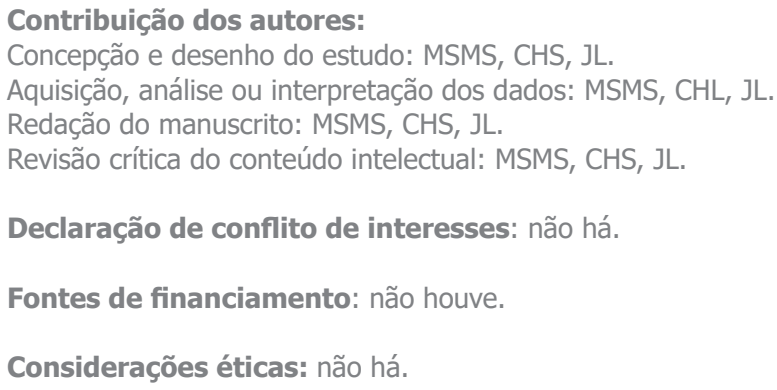

Licença CC BY-NC atribuição não comercial. Com essa licença é permitido acessar, baixar (download), copiar, imprimir, compartilhar, reutilizar e distribuir os artigos, desde que para uso não comercial e com a citação da fonte, conferindo os devidos créditos de autoria e menção à Reciis. Nesses casos, nenhuma permissão é necessária por parte dos autores ou dos editores. 


\section{Introdução}

O impacto da pesquisa e a efetiva utilização dos seus resultados é um assunto de permanente interesse tanto no ambiente acadêmico como no de gestão e governo. Em tempos de farta comunicação e publicação de artigos científicos continua havendo dificuldades para integrar e propiciar uma ponte efetiva entre a pesquisa, a prática e a política. Diante disso, muitas instituições acadêmicas e governos têm definido que a translação da pesquisa é uma prioridade para a saúde.

Surge nesse contexto uma discussão renovada de problemas muito antigos, agora denominados de knowledge translation (KT). Trata-se de um processo que busca melhorar a qualidade da saúde das pessoas por meio do maior aproveitamento dos resultados das pesquisas e que nada mais é que o antigo sonho de que a ciência tem o poder de produzir conhecimento capaz de tirar todos da miséria, da ignorância e do erro' ${ }^{1}$.

Esse processo ressurge na sociedade do conhecimento, com o compromisso de melhorar a transferência e a utilização do conhecimento mediante a bem difundida ideia da saúde e políticas de saúde baseadas e/ou informadas por evidências científicas.

Dois grandes passos têm sido visualizados como definitivos para levar a KT ao sucesso: a aplicação, na prática clínica, dos achados da investigação básica, isto é, dos resultados da investigação experimental realizada em laboratórios; e a transformação do conhecimento científico em evidências que possam se tornar generalizáveis e aplicáveis em decisões e políticas de saúde.

Embora essas alternativas sejam de conhecimento geral, existem as mais diversas barreiras, como, por exemplo, a falta de tempo e disponibilidade de ambos os atores - cientistas e formuladores de políticas - para manipular o excesso de informações, muitas vezes fragmentadas e dispersas. O que revela que a simples disseminação da informação em canais formais, em formatos clássicos e linguagem técnica, tais como são os artigos científicos, não tem sido a solução para esse problema. Aspectos mais complexos devem ser considerados, como o devido ajuste que precisa existir entre as necessidades de informação para um problema prático e a correspondente elaboração de perguntas de pesquisa exequíveis. Os resultados e suas implicações precisam ser colocados de forma acessível e comunicados aos grupos de interesse. Consequentemente, as estratégias de disseminação e de implementação deveriam ser elaboradas levando em conta a complexidade da situação na prática² .

O estudo partiu da necessidade de compreender e distinguir as diferentes terminologias encontradas na literatura sobre essa temática e de conhecer qual seria a abordagem dos estudos nacionais. Porém, muito pouco foi encontrado na literatura brasileira da área de saúde, o que motivou a escrita deste ensaio. Este artigo pretende contribuir para a discussão e compreensão, bem como embasar projetos e atividades que proponham uma intervenção com o objetivo de propiciar um melhor trânsito entre conhecimento e decisões de saúde.

Para alcançar tal objetivo e para além do estudo da terminologia empregada, ampliou-se o olhar sobre o conceito e o processo de knowledge translation na área da saúde, enfatizando os modelos de utilização do conhecimento e das evidências encontradas por meio de pesquisas e seu papel nas decisões de saúde. 


\section{Percurso metodológico}

A literatura da temática na área de saúde foi explorada basicamente nas bases de dados Medline/ PubMed, complementada por uma busca nas referências dos artigos e livros encontrados. Dois livros ${ }^{3,4}$ de autores canadenses e ingleses, que foram utilizados como base, auxiliaram a percorrer as concepções multidisciplinares e a perspectiva sociológica, explorando também desafios e limites do uso do conhecimento nos diversos contextos da saúde.

O conceito de knowledge translation (KT) não tem uma definição consensual na literatura da área de saúde, e tanto a tradução para o português como o seu significado não estão claramente estabelecidos na literatura brasileira. Consequentemente, a primeira questão que aparece ao abordar o tema é sobre como estaria adaptado o termo do inglês. Translation pode ser interpretado como tradução, mas também como translação, transformação ou transferência. Com o intuito de encontrar um suporte formal para o uso das palavras adequadas, efetuou-se uma busca no tesauro Medical Subject Headings (MeSH), da base de dados bibliográfica Medline, principal base da área de saúde.

O MeSH é um vocabulário controlado que organiza a terminologia médica em categorias hierárquicas e se baseia nos temas abordados na literatura. Por esta razão, é permanentemente revisado e atualizado, acompanhando o surgimento de novos assuntos e conceitos que se expressam com descritores ${ }^{5}$. No MeSH, knowledge translation foi encontrado como um termo de entrada (referência cruzada) do descritor 'Translational Medical Research'. Este termo se encontra na árvore hierárquica do descritor 'Biomedical Research' e foi agregado ao tesauro em 2012.

No tesauro utilizado pelas bases de dados da Biblioteca Virtual em Saúde (BVS), chamado Descritores em Ciências da Saúde (DeCS), o qual é uma adaptação do MeSH, o descritor 'Translational Medical Research' se traduz para o português como 'Pesquisa Médica Translacional', sendo sua definição uma tradução exata da que se encontra no MeSH: "Aplicação das descobertas geradas por pesquisa de laboratório e em estudos pré-clínicos para o desenvolvimento de pesquisa clínica e estudos em humanos. Uma segunda área da pesquisa translacional envolve o aprimoramento da adoção de boas práticas"”.

A literatura que se recupera com esse descritor na base de dados Medline, grosso modo, versa sobre artigos que aplicaram o conceito apresentado por Castro e Silva e Cardoso $^{7}$ e que condiz com a definição no tesauro: o processo de transferir a pesquisa básica do laboratório ao cenário da prática clínica (da bancada do laboratório para a cama do paciente). Esses estudos mostram experiências pontuais dessa translação (ver, por exemplo, Tsukumo ${ }^{8}$ ). Assim, percebe-se que esse é um aspecto do tema que vem sendo desenvolvido na área médica.

Uma busca mais abrangente na literatura nacional procurando conhecer a tradução mais utilizada e o conceito adotado resultou muito escassa, porém demonstrou certa tendência crescente. Na base de dados Lilacs e na biblioteca digital SciELO, buscaram-se estudos usando diferentes combinações de termos da seguinte forma: ("translação do conhecimento" OR "transferência do conhecimento" OR "tradução do conhecimento" OR ((translação OR tradução OR transferência) AND conhecimento). Recuperaram-se apenas 28 trabalhos antes de fazer a triagem de pertinência e todos eram posteriores a 2009. Acrescentando a expressão em inglês 'knowledge translation', para o caso de que houvesse outras formas de tradução, e aproveitando que a base é trilíngue, e, portanto, todos têm título e resumo em inglês, recuperaram-se mais alguns trabalhos. Quando usado o termo 'translacional', o número aumenta para 79, ainda antes da triagem. Uma análise do conteúdo desses artigos mostra que são pertinentes 22 estudos brasileiros. Porém, apenas seis trabalhos podem ser considerados teóricos e discutem o conceito $^{9-15}$. A maioria dos outros artigos consistiu em relatos de experiências de implementação da medicina translacional, e os outros eram editoriais. 


\section{Discussão dos resultados}

Os resultados mostram que há um interesse tímido ainda sobre o tema no país na área de saúde, a julgar pela quantidade dos trabalhos recuperados nas bases de dados pesquisadas. São poucos os que trazem à discussão aspectos tais como: o conceito, as formas de implementar a translação do conhecimento, os entraves para a translação, a análise do uso da evidência nas decisões e políticas de saúde.

Quanto à terminologia utilizada pelos autores, observou-se durante a busca que existe muita variedade. Tal impressão se corrobora com os achados do trabalho dos pesquisadores canadenses da MacMaster University, liderados por McKibbon $^{16}$. Eles fizeram um levantamento mundial dos estudos publicados sobre o tema durante o ano de 2006, para saber a quantidade e a frequência de termos usados para referir KT. Eles encontraram 581 artigos sobre o assunto, dos quais 152 eram teóricos e 201 versavam sobre aplicação da KT. Ademais, outras 100 diferentes expressões foram identificadas, das quais 46 estavam nos títulos e resumos. As 10 expressões mais usadas foram: 'opinion leader', 'linkage and exchange', 'knowledge transfer', 'knowledge diffusion', 'knowledge utilization', 'knowledge synthesis', 'knowledge dissemination', 'information science' e 'effectiveness research'. Grimshaw e colaboradores ${ }^{17}$, posteriormente, citaram também: 'knowledge transfer and exchange', 'innovation diffusion', 'implementation research', 'research utilization', 'evidence-informed policy' e 'evidence-informed health systems'.

Outra expressão frequente é 'implementação da pesquisa', porém estudos a definem mais como uma atividade do que como um conceito. A implementação da pesquisa visa descobrir métodos eficientes para uma intervenção comportamental na melhoria da prática dos profissionais de saúde ${ }^{18}$.

A primeira observação com relação à busca na literatura internacional é de que 'knowledge translation' $\mathrm{e}$ 'translação da pesquisa' ou 'saúde translacional' não são sinônimos. Os estudos que abordam a translação da pesquisa ou saúde translacional estão se referindo a algo muito concreto e pontual: uma atividade direcionada a pôr em prática uma descoberta ou constatação científica da ciência básica que pode ser utilizada nas pesquisas clínicas, um movimento que vai do laboratório ou da pesquisa em animais para os pacientes.

Os estudos sobre KT, por outro lado, são teóricos, abordam o fenômeno que rodeia as atividades de pesquisa e sua inter-relação com as necessidades da prática, mostrando que nesse movimento importam mais a informação e as evidências do que os dados e os artigos.

No entanto, ambos os tipos de estudo têm em comum seu objetivo, que é o uso dos resultados da pesquisa. Seria possível pensar que muitas atividades de pesquisa translacional sendo levadas a cabo contribuem para conseguir o objetivo da knowledge translation? A resposta parece ser que não, pois, embora seja possível implementar KT por meio de atividades pontuais, essas atividades deveriam ser de caráter político, público e social.

Apesar de ficarem claras as diferenças entre os conceitos, alguns autores adotam definições de forma a englobar todo o processo. Segundo Sung e colaboradores ${ }^{19}$ e Grimshaw e colaboradores ${ }^{17}$, a expressão translação da pesquisa pode ser dividida em dois blocos: T1 - translação de pesquisa biomédica básica para o conhecimento e a ciência clínica; novos entendimentos sobre os mecanismos das doenças para desenvolver novos métodos diagnósticos, tratamentos e prevenção e seu primeiro teste em humanos; e T2 - translação da ciência e do conhecimento clínico para a melhoria da saúde. Em T1 ocorre ainda o processo de construção da ciência, enquanto em T2 há um conhecimento produzido e seu objetivo é melhorar a saúde ${ }^{17,20}$.

Há, porém, uma forte tendência na literatura a adotar a definição do órgão governamental Canadian Institutes of Health Research (CIHR), para o qual a KT é um "processo dinâmico e interativo que inclui síntese, disseminação, intercâmbio e aplicação ética do conhecimento para melhorar a saúde”21 (tradução nossa). O processo envolve pesquisadores ou produtores de conhecimento e usuários deste conhecimento e seu funcionamento. Interações e complexidade variam de acordo com o tipo de pesquisa e sua finalidade, assim como também com as necessidades e particularidades do usuário final ${ }^{21}$. 
O conceito de KT implica a produção e a gestão de resultados de pesquisa, translação desses resultados ou propriamente translação de pesquisa. Este processo envolve a gestão da informação em saúde, área que muito tem a contribuir por meio da busca, seleção, compilação, avaliação e disseminação da informação que serve de alicerce para a decisões em saúde.

Grimshaw e colaboradores ${ }^{17}$ definem esse conceito complexo de uma forma simplificada - é a ação de "assegurar que as partes interessadas (stakeholders) estejam cientes e utilizem a evidência de pesquisa para informar suas decisões de saúde"17 (tradução nossa). As partes interessadas podem ser os pacientes, a comunidade, os profissionais de saúde, os administradores locais, os da política nacional, órgãos reguladores, a indústria, os financiadores de pesquisa e os pesquisadores. Graham e colaboradores ${ }^{22}$ denominam a sua operacionalização da seguinte maneira: conhecimento para a ação (knowledge to action), expressão que se ajusta ao discurso da Organização Mundial da Saúde (OMS) em sua publicação World Report on Knowledge for Better Health ${ }^{23}$, na qual há um capítulo dedicado às ações para propiciar o uso da pesquisa na prática.

A literatura recuperada nas buscas e analisada, por fim, permite compreender que há duas expressões que identificam questões diferentes: pesquisa translacional e translação do conhecimento. Conclui-se que esta última envolve um processo muito mais complexo sobre o qual discorre este artigo. Com base na bibliografia selecionada adota-se, neste trabalho, a expressão 'translação do conhecimento' (TC) como a denominação em português. O entendimento é de que se trata de um processo ativo e manipulável, mas é também uma estratégia ${ }^{24}$ que procura propiciar a utilização dos resultados das pesquisas para obter melhores resultados em relação à saúde das pessoas. A translação, neste sentido, implica mais que apenas a disseminação ou difusão de resultados da pesquisa, é também uma atividade de avaliação da qualidade dos resultados da pesquisa e verificação da sua aplicabilidade. Um processo que começa na criação do novo saber e vai até sua aplicação, e que pretende influenciar mudanças de comportamento. Portanto, não ocorre de forma espontânea; ele precisa ser implementado ${ }^{24}$, e, para sua efetivação, mais que uma ideologia, ele demanda atitudes e decisões políticas.

\section{Os modelos de translação do conhecimento}

\section{Perspectiva sociológica}

Alguns modelos de TC são encontrados na literatura com diferentes nomenclaturas e pontos de vista. Dickinson $^{1}$ apresenta a perspectiva sociológica da translação e do uso do conhecimento situando-a na época imediatamente posterior à Segunda Guerra Mundial, a partir da qual ele propõe uma subdivisão de modelos em: tecnocrático, decisionista (tradução nossa de decisionistics) e pragmático.

No modelo tecnocrático, a ciência é vista como a força motriz do progresso humano, e o desenvolvimento e a aplicação do conhecimento científico podem solucionar os problemas da vida do homem ${ }^{1}$. Nesse modelo, a comunidade política e a de pesquisadores são vistas como separadas por valores, interesses e processos decisórios diferentes e tal separação é tida como insuperável, dado o caráter subjetivo e irracional do político. Os corruptos são os que impedem o sonho tecnocrático. O princípio imperante na sociedade pós-industrial é de que o conhecimento científico deve ser o alicerce para o planejamento, a inovação tecnológica, a formulação de políticas e o crescimento econômico, motivos pelos quais é conhecida como a sociedade do conhecimento.

Nesse contexto, surge uma espécie de 'tecnologia intelectual' na qual predominam as classes profissionais e técnicas com uma visão de que o 'conhecimento se organiza como trabalho', de forma profissional portanto, como afirma Freidson citado por Dickinson ${ }^{1}$. A medicina, por exemplo, representa o arquétipo de profissão cujo conhecimento imprime o poder, controle e domínio não apenas sobre pacientes e outros profissionais de saúde, mas também sobre as políticas. Os procedimentos de diagnóstico e de tratamento foram vistos como formas de controle social na sociedade moderna. O domínio exercido pelos profissionais da medicina 
na formulação e implementação das políticas de saúde foi visto como uma ameaça à democracia pelo exercício de um "governo privado" ou "um Estado dentro do Estado", segundo Taylor, citado por Dickinson'.

No modelo tecnocrata, os cientistas devem ser como engenheiros que, de forma muito racional, planejam e solucionam os problemas da sociedade, ou, propriamente, um governo de expertos científicos e técnicos. Neste sentido, para que ocorra uma efetiva translação e, consequentemente, o uso do conhecimento científico, deve haver a unificação entre ciência e governo. As críticas irão chamar esse modelo de 'cientificismo', pela convicção de que somente a ciência produz a verdade e que toda outra evidência que não seja científica é falsa, conforme Habermas ${ }^{\mathrm{i}}$ apud Dickinson ${ }^{1}$.

O modelo decisionista sobre utilização e translação do conhecimento traduz a abordagem sociológica dominante da época. Considera que tanto as comunidades de políticos como as de pesquisadores cumprem uma função social, havendo, porém, uma divisão no trabalho que ambos exercem. Na política, tomam-se as decisões de acordo com os objetivos de cunho político, e os cientistas se ocupam de determinar a forma racional de alcançar tais objetivos. Por isso, a decisão sobre a importância das escolhas nesse modelo não é racional; tratase de uma decisão entre as opções dadas (decisionista), na qual pouco podem interferir os argumentos mais convincentes, posto que essa atitude é tão subjetiva quanto irracional, segundo ideias de Habermas apresentadas por Dickinson ${ }^{1}$. Ela também escapa ao domínio da ciência, pois, como diz Lomas, a melhor escolha não pode ser determinada objetivamente ${ }^{1}$. Sendo assim, a atuação do cientista deve estar preservada das influências do poder e de cair na demagogia, devendo manter a objetividade. A ciência, contudo, não está livre de críticas quanto à sua produção de conhecimento, muitas vezes visto como trivial e irrelevante para a prática e, quase sempre, confuso e contraditório para a utilização pelos responsáveis pela tomada de decisão ou da população.

Os cientistas refutaram essas críticas argumentando que a utilização do conhecimento nem sempre é tão evidente, pois tal uso pode-se refletir em outras esferas diferentes daquelas em que foi produzido, como na educação, por exemplo. O uso do conhecimento pode ser conceitual, por isso foi também chamado de modelo de esclarecimento ${ }^{1}$ e, por vezes, pode ser apenas simbólico ou conveniente para dar suporte a posicionamentos e interesses pré-estabelecidos.

Contudo, as pesquisas mostram que a credibilidade e veracidade do conhecimento gerado pela ciência não garantem seu emprego, e que ele será menos utilizado quando entrar em conflito com tais interesses. Portanto, a melhor forma de propiciar a translação do conhecimento científico nesse modelo se daria mediante a colaboração entre pesquisadores e tomadores de decisão, levando-se em conta a dificuldade de manter o "mito da neutralidade" da ciência nessa colaboração, como mostra Dickinson'.

O modelo pragmático se destaca pela visão de que, na formulação e implementação de políticas, deve existir a participação democrática do público e da ciência, afirma Habermas ${ }^{\mathrm{ii}}$ apud Dickinson ${ }^{1}$. De acordo com os dois modelos anteriormente apresentados, o público tem pouca ou nenhuma participação no processo de TC. No modelo tecnocrático, o público participa como consumidor de serviços, praticamente um cliente do sistema de saúde; e, no decisionista, participa por meio das eleições, aprovando as decisões da elite no poder. O contexto que se apresenta está marcado pela desilusão do público e pelo descrédito relativos às atitudes das elites científicas, políticas e profissionais desse sistema democrático. O motivo, em grande parte, se deve à omissão de consulta prévia à população para a implementação de novas tecnologias e procedimentos que têm implicações importantes na vida das pessoas. Nesse contexto, marcado por um sentimento de insegurança e de injustiça, que propiciam a reivindicação de participação, surge o modelo pragmático de translação e de uso do conhecimento, alinhado às questões éticas relacionadas à aplicação da ciência e tecnologia na sociedade.

Segundo Dickinson ${ }^{1}$, nesse modelo, três questões fundamentais são relevantes: 1) A mudança do conceito de transferência para o de translação de conhecimento, que, antes visto como produto da

i Habermas J. Towar a rational society: student protest, science, and politics. London: Heinemann; 1971.

ii Habermas J. Towar a rational society: student protest, science, and politics. London: Heinemann; 1971. 
ciência, passa a ser entendido como um processo comunicacional socialmente construído. A TC se dá na atividade de comunicação para demonstrar que os novos conhecimentos e tecnologias surgem para atender necessidades e interesses pré-existentes, assim como para redefinir uma nova compreensão da relevância do conhecimento gerado. O 'aprendizado social' que ocorre na TC pressupõe a participação do público, ou seja, daqueles que serão afetados por esse novo conhecimento. 2) A compreensão de que a TC é necessária para múltiplas áreas e não apenas para aquela especialidade na qual o conhecimento ou tecnologia foi gerado. Inclusive, deve ocorrer para o público. 3) O entendimento de que a TC não deve acontecer em uma única direção e dentro de especialidades pré-estabelecidas, mas que deve ser um processo de comunicação de duas vias, com o propósito de propiciar um entendimento mútuo entre ciência e destinatários do conhecimento. No modelo pragmático, por fim, há um discurso ético que pressupõe o uso justo desse novo conhecimento, como, por exemplo, por intermédio da implementação de políticas que contemplem, fundamentalmente, o ponto de vista do usuário final ou daqueles que serão afetados pelo novo conhecimento ou tecnologia.

Este modelo pressupõe a participação do público na atividade política e assento nas instâncias deliberativas. Uma afirmação que deixa em evidência os diversos impedimentos que obstaculizam o ideal da aproximação justa e democrática entre geradores de conhecimento, implementadores e destinatários. Tais obstáculos podem ser: as informações repassadas pelos especialistas contêm uma linguagem não facilmente acessível aos não especialistas; a enorme quantidade de novos conhecimentos gerados constantemente; a ciência privada ou custeada por agências que produzem conhecimento proprietário, com as consequentes derivações desta tendência. Também dificultam sobremaneira a abordagem instrumental da TC associada aos modelos tecnocráticos e decisionista, além do desinteresse de participação política do público.

Para uma compreensão mais abrangente das concepções teóricas sobre o tema, merece destaque a contribuição de Eastbrooks e colaboradore ${ }^{18}$, que publicaram um guia onde analisam cinco teorias de TC:

a) A teoria da difusão da inovação, cujo objetivo é explicar como se espalham as novas ideias. Entende a difusão como o processo de comunicação da inovação por meio de diversos canais, tomando como base o fato de que "os indivíduos progridem em cinco etapas: conscientização, persuasão, decisão, implementação e adoção"18. Uma vez adotada, a inovação se espalha por meio de vários canais de comunicação.

b) Marco conceitual de desenvolvimento, disseminação e utilização da pesquisa com base nos estudos de Havelock ${ }^{i i i}$ e colaboradores, citado por Eastbrooks et al. ${ }^{18}$. Eles identificavam duas forças sociais relevantes na época: a explosão do conhecimento científico e uma forte expectativa sobre a utilidade deste conhecimento para os responsáveis pelas tomadas de decisão. Havelock argumentou que, para promover a disseminação e transferência de informações e conhecimento científico, este deveria ser construído e institucionalizado por intermédio de uma integração sistemática, criando uma ciência acessível e dinâmica, estabelecendo relações de confiança entre pesquisadores e profissionais e formuladores de políticas.

c) A revisão sistemática de Greenhalgh e colaboradores ${ }^{25}$ de como espalhar boas ideias apresenta uma lista de características que devem ter as pesquisas que buscam identificar lacunas de conhecimento: "ser orientadas pela teoria, ser um processo, em vez de um 'pacote', ser ecológicas, abordar definições, medidas e ferramentas comuns, ser colaborativas e coordenadas, multidisciplinares e multimétodos, meticulosamente detalhadas e participativas" 25 .

d) O modelo de promoção de ações em pesquisa de serviços de saúde com base nos estudos de Kitson iv citado por Eastbrooks et al. ${ }^{18}$. Eles argumentaram que, para haver uma implementação da pesquisa bemsucedida, pelo menos três fatores devem estar em perfeita relação: a evidência, o contexto favorável à mudança e os facilitadores devidamente qualificados.

\footnotetext{
iii Havelock RG. Planning for innovation through dissemination and utilization of knowledge. Ann Arbor, MI: Center for Research on Utilization of Scientific Knowledge; 1969.

iv Rycroft-Malone J, Seers K, Titchen A, Harvey G, Kitson A, McCormack B. What counts as evidence in evidence-based practice? J Adv Nurs 2004; 47:81-90.
} 
e) O Modelo de Uso de Pesquisa de Ottawa (OMRU - Ottawa Model of Research Use). Os proponentes identificam seis elementos que devem estar presentes nas iniciativas de promover a implementação dos resultados da pesquisa na prática: o ambiente da prática, os pesquisadores, a inovação baseada em evidências, as estratégias de transferência, a adoção das evidências e os resultados. E estes elementos não devem ser apenas identificados, devem ser também monitorados e avaliados durante e após o processo de implementação ${ }^{18}$.

\section{Modelos de translação do conhecimento na sociedade do conhecimento}

Na era da sociedade do conhecimento, há um uso mais fácil e intenso do conhecimento e uma ênfase maior na disseminação e na produção nele baseada. Porém, nesse cenário, surge um paradoxo, como argumentam Denis, Lehoux e Champagne ${ }^{26}$ : "o surgimento de uma sociedade baseada no conhecimento parece estar vinculado a um enfraquecimento da prática da ciência em sua forma mais tradicional".

As transformações no modelo de TC na área de saúde trouxeram novos atores, mudando as relações e colocando novos desafios. Cinco modelos, abordando a relação entre ciência e prática e os determinantes do uso do conhecimento, são descritos por Denis, Lehoux e Champagne ${ }^{26}$.

- O modelo conduzido pelo conhecimento (knowledge-driving) considera que o papel da ciência é a produção acumulativa e desinteressada de conhecimento, posto que o valor do conhecimento está em si mesmo. Nesse sentido, o confinamento da ciência é tido como aceitável, ao mesmo tempo que o sistema de colegiado e de revisão por pares garante a adequação do conhecimento que terá sua difusão garantida desde que este conhecimento seja legítimo e rigorosamente elaborado;

- O modelo solução de problemas (problem-solving) concebe a TC como um processo no qual os profissionais que exercem a prática demandam aos cientistas investigações para resolver problemas do seu dia a dia. Existe uma legitimação dessa demanda e uma expectativa de que a ciência, necessariamente, responderá a ela. O mundo da prática e da ciência são universos paralelos neste modelo, no qual se presume que, por exemplo, se um cientista é competente em um determinado assunto, será inevitavelmente requisitado pelos profissionais. Diferentemente do modelo anterior, o conhecimento aqui é considerado valioso quando serve para algum propósito ou solução de problemas da prática.

Uma extensão deste modelo foi encontrada em Shonv, citado por Denis, Lehoux e Champagne ${ }^{26}$, em sua obra sobre o profissional reflexivo, onde trata do processo de desenvolvimento e utilização do conhecimento. Shon considera que a ciência tem sido ineficiente em produzir conhecimento para resolver os dilemas da sociedade, sendo isto consequência da existência de dois 'reinos' separados, o da ciência e o da prática. O autor observa que o conhecimento que vem da experiência é visto como menos valioso do que o conhecimento sistemático produzido pelos pesquisadores. Para Shon, pelo contrário, o conhecimento nasce predominantemente da prática e da experiência sendo posteriormente formalizado pela ciência. O profissional que reflete sobre sua prática produz conhecimento. O ambiente da prática clínica é um bom exemplo disso, observando e examinando cada paciente, o clínico produz hipóteses e novo conhecimento ${ }^{26}$.

- O modelo esclarecedor (einlightenment), da mesma forma que o modelo knowledge-driven, atribui ao conhecimento um valor em si mesmo, sendo que o maior benefício de sua produção e disseminação estará em desvendar a compreensão do mundo. O conhecimento tem, assim, um valor intelectual e cognitivo. Neste modelo, a circulação do conhecimento é de caráter informal e não estruturada e poderá penetrar na sociedade de forma inesperada, mais no sentido de um bem cultural e não como uma ferramenta própria para resolver problemas cotidianos. O conhecimento não é utilizado de forma instrumental; os conceitos e ideias são como 'entidades nômades' que circulam de uma área para outra sem uma previsão programada. Este modelo reforça a visão de que o confinamento da ciência é bom porque assim produz o desenvolvimento e a transformação da visão do mundo;

v Shon DA. The reflective practitioner: how professionals think in action. New York: BasicBooks; 1983. 
- O modelo estratégico (strategic) atribui ao conhecimento a qualidade de ser um recurso acumulável, intercambiável ou utilizável entre os diversos protagonistas. O valor do conhecimento se dá em certos contextos sociais ou organizacionais, quando sua utilização é considerada estratégica, posto que não tem valor até não ser especificamente útil. Se o conhecimento é adequado ao projeto e aos objetivos, ele será um recurso importante para a implementação ou poderá ser manipulado para legitimar posicionamentos pessoais ou, ainda, conseguir vantagens dentro da organização ou na sociedade. Esta ideia traz implícita uma visão do uso oportunista do conhecimento na relação entre os cientistas (teóricos) e os que o colocam em prática. Não obstante, há de se levar em conta que, no planejamento estratégico, o conhecimento científico poderá não só moldar a negociação, como também contribuir para as decisões. Este modelo requer a atuação de um líder capaz de articular o uso do conhecimento com sua contribuição para a tomada de decisões na sociedade e nas organizações;

- O modelo interativo ou deliberativo (interactive or deliberative) pode ser visto como uma síntese e uma extensão do modelo esclarecedor e do estratégico. Partindo da base de que a coprodução e cointerpretação do conhecimento entre profissionais e cientistas é fundamental, estabelece-se que deve haver um alto nível de cooperação entre as duas comunidades. Dessa forma, o relacionamento entre elas torna-se simétrico e não hierárquico. Ao considerar o conhecimento como uma construção social carente de validação do público, o modelo persegue a democratização do seu uso. Neste modelo, o conhecimento adquire valor através da sua interpretação, e, para isso, as relações entre os cientistas e o público devem se organizar para que aconteça a livre circulação do conhecimento e compartilhamento de sua interpretação. O papel dos que exercem a prática, neste modelo, é mais ativo, tanto na formulação das perguntas de pesquisa como na interpretação, numa ampla cooperação.

No Quadro 1, encontra-se reproduzida a tradução do quadro comparativo dos cinco modelos elaborado por Denis, Lehoux e Champagne ${ }^{26}$. Neste quadro, os autores chamam a atenção para uma visão positiva dos teóricos dos cinco modelos quanto à difusão do conhecimento científico na sociedade, excetuando Shon ${ }^{\text {vi }}$, quem tem uma visão diferente, pois considera que a prática é a principal impulsionadora do surgimento do conhecimento.

Os autore ${ }^{26}$ destacam ainda, neste quadro, o papel dos atores dessa relação marcada por uma hierarquia social e limites claros, na qual os cientistas são os produtores do conhecimento e os que o utilizam na prática são os consumidores. Sendo assim, uma maior fluidez na translação do conhecimento demandaria estratégias de comunicação, difusão e persuasão, bem como políticas que promovam a literacia científica e cultural da sociedade. 
Quadro 1 - Quadro comparativo entre os cinco modelos

\begin{tabular}{|c|c|c|c|c|c|}
\hline & $\begin{array}{l}\text { Conduzido pelo } \\
\text { conhecimento }\end{array}$ & $\begin{array}{l}\text { Resolução de } \\
\text { problemas }\end{array}$ & Esclarecedor & Estratégico & Deliberativo \\
\hline $\begin{array}{l}\text { Conceito } \\
\text { de conhe- } \\
\text { cimento }\end{array}$ & $\begin{array}{l}\text { O conhecimento } \\
\text { desinteressado } \\
\text { é produzido } \\
\text { pelos devotados } \\
\text { cientistas }\end{array}$ & $\begin{array}{l}\text { O conhecimento } \\
\text { útil é produzido } \\
\text { colocando } \\
\text { restrições aos } \\
\text { cientistas } \\
\text { Para Shon, o } \\
\text { conhecimento } \\
\text { emerge da } \\
\text { prática }\end{array}$ & $\begin{array}{l}\text { O conhecimento } \\
\text { é construído } \\
\text { com ideias que } \\
\text { fluem de uma } \\
\text { área para outra } \\
\text { e através do } \\
\text { tempo }\end{array}$ & $\begin{array}{l}\text { O conhecimento } \\
\text { é um recurso } \\
\text { estratégico } \\
\text { que pode ser } \\
\text { acumulado, } \\
\text { intercambiado } \\
\text { ou aplicado } \\
\text { em situações } \\
\text { específicas }\end{array}$ & $\begin{array}{l}\text { O conhecimento } \\
\text { é coproduzido e } \\
\text { co-interpretado }\end{array}$ \\
\hline $\begin{array}{l}\text { Interações } \\
\text { entre ciência } \\
\text { e prática }\end{array}$ & $\begin{array}{l}\text { Não são } \\
\text { necessárias as } \\
\text { interações; a } \\
\text { sociedade é vista } \\
\text { como receptora } \\
\text { passiva }\end{array}$ & $\begin{array}{l}\text { Os profissionais } \\
\text { devem dizer } \\
\text { aos cientistas } \\
\text { quais são os } \\
\text { problemas } \\
\text { Para Shon, os } \\
\text { profissionais } \\
\text { reflexivos estão } \\
\text { aptos a resolver } \\
\text { seus próprios } \\
\text { problemas }\end{array}$ & $\begin{array}{l}\text { A fertilização } \\
\text { cruzada das } \\
\text { visões de } \\
\text { mundo dos } \\
\text { cientistas e } \\
\text { profissionais } \\
\text { deve ser } \\
\text { buscada em } \\
\text { diferentes fases } \\
\text { do processo de } \\
\text { produção do } \\
\text { conhecimento }\end{array}$ & $\begin{array}{l}\text { O enquadramento } \\
\text { do conhecimento } \\
\text { estratégico } \\
\text { pelas partes } \\
\text { interessadas deve } \\
\text { orientar o trabalho } \\
\text { dos cientistas }\end{array}$ & $\begin{array}{l}\text { A crescente } \\
\text { interação e } \\
\text { cooperação } \\
\text { entre cientistas } \\
\text { e profissionais } \\
\text { deve ser vista } \\
\text { através do } \\
\text { processo de } \\
\text { produção do } \\
\text { conhecimento }\end{array}$ \\
\hline $\begin{array}{l}\text { Determinan- } \\
\text { tes da } \\
\text { utilização }\end{array}$ & $\begin{array}{l}\text { Uma aplicação } \\
\text { útil derivará da } \\
\text { boa ciência; } \\
\text { a utilização é } \\
\text { responsabilidade } \\
\text { dos profissionais }\end{array}$ & $\begin{array}{l}\text { As necessidades } \\
\text { dos profissionais } \\
\text { devem ser } \\
\text { preenchidas } \\
\text { pelos cientistas; } \\
\text { a utilização é } \\
\text { mais ou menos } \\
\text { consequência } \\
\text { direta } \\
\text { Para Shon, a } \\
\text { reflexividade e a } \\
\text { definição criativa } \\
\text { do problema } \\
\text { determinam o } \\
\text { uso }\end{array}$ & $\begin{array}{l}\text { O conhecimento } \\
\text { penetra na } \\
\text { sociedade } \\
\text { através de } \\
\text { um processo } \\
\text { imprevisível } \\
\text { de interações; } \\
\text { a utilização } \\
\text { é, então, } \\
\text { conceitual }\end{array}$ & $\begin{array}{l}\text { O conhecimento } \\
\text { pode servir } \\
\text { a diferentes } \\
\text { finalidades; a } \\
\text { utilização deriva } \\
\text { da negociação } \\
\text { entre profissionais } \\
\text { e cientistas } \\
\text { orquestrados por } \\
\text { uma terceira parte } \\
\text { de forma racional } \\
\text { e estratégica }\end{array}$ & $\begin{array}{l}\text { O conhecimento } \\
\text { é aplicado } \\
\text { quando é } \\
\text { abertamente } \\
\text { debatido; a } \\
\text { utilização é } \\
\text { um resultado } \\
\text { negociado. }\end{array}$ \\
\hline
\end{tabular}

Fonte: Adaptado de Denis, Lehoux e Champagne ${ }^{26}$.

Segundo Almeida e Báscolo ${ }^{27}$, há um pressuposto subjacente a esses modelos, que é o de pensar a pesquisa e a formulação de políticas como processos racionais e lógicos. A concepção de que os pesquisadores formulam as perguntas certas, elaboram os projetos, conduzem os estudos rigorosamente e fazem circular os resultados pelos meios adequados e que, por sua vez, os responsáveis pelas tomadas de decisão leem esses relatórios, entendem os resultados e suas implicações e atuam para corrigir ou adaptar suas decisões conforme a pesquisa é, no mínimo, ingênuo porque tal processo não ocorre de forma tão linear na vida real. É fato que o conhecimento e a informação devem fazer parte das decisões e argumentações dos responsáveis por elas, mas o processo ocorre de forma difusa, com o acúmulo de informações sobre determinado assunto, influenciado pela conjuntura política e por uma série de outros fatores. 


\section{A translação do conhecimento e o processo decisório}

\section{O papel das evidências científicas}

A ciência, no processo de TC, contribui com a geração de evidências na forma de resultados de pesquisas, e, ao seguir um método reconhecido, verificável e reprodutível, o estudioso produz o que se chama de evidência científica. Mas o que é uma evidência? Analisando o conceito de evidência, entende-se que esta tem um papel central na compreensão do conhecimento e da racionalidade; somente se tem conhecimento quando existe um convencimento verdadeiro baseado em uma evidência forte. Assim, crença racional é quando se acredita com base em uma adequada evidência ${ }^{28}$. Para a filosofia da ciência, a evidência é aquilo que confirma ou refuta as teorias cientificas e constitui, assim, o fundamento para se decidir racionalmente. Em vista disso, a compreensão da evidência seria indispensável para entender o funcionamento adequado do fazer científico ${ }^{29}$. O argumento político, no entanto, pode contradizer as razões científicas, pois exige outros elementos além do científico, de modo que esse tipo de conhecimento somente se tornará uma evidência quando usado para sustentar as declarações políticas ${ }^{30}$.

Uma evidência científica, por sua vez, é entendida como o conhecimento explícito, sistemático, que utiliza métodos transparentes, que precisa de confirmação, e, para que isso ocorra, a experimentação passa a ser um dos caminhos. Desse modo, a "evidência [...] pode ser definida como as informações ou os fatos obtidos sistematicamente, isto é, obtidos de tal forma que são replicáveis, observáveis, acreditáveis, verificáveis ou basicamente sustentáveis”31.

O conceito de evidência científica, no contexto da medicina, foi analisado por Upshur ${ }^{32}$, que alega que as propriedades mais marcantes da evidência nessa área mostram que sua estrutura é 'falibilista' (fallibilistic). O falibilismo (fallibilism) é uma teoria que sustenta que "qualquer uma das nossas crenças ou opiniões sobre o mundo externo podem vir a ser falsas e que uma grande nuvem de incerteza assombra nossas deliberações" ${ }^{2}$ (tradução nossa).

Segundo Upshur ${ }^{22}$, as características da evidência na área médica são a provisoriedade, revogabilidade, incompletude, ser emergente, ser limitada, coletiva e assimétrica. As duas primeiras características dão uma clara ideia de que, raramente, uma evidência médica trará certeza absoluta e que poderá sempre ser revista à luz de novas evidências. Segundo a autora, a provisoriedade e revogabilidade das evidências pode ser ilustrada por meio do exemplo relativo à causa e ao tratamento da úlcera péptica. Nos anos 1970, as evidências sobre a etiologia e o tratamento da úlcera péptica professavam que esta tinha origem no estresse e que devia ser tratada com dieta branca (leite). Já nos anos 1980, quando surge a cimetidina, a causa passou a ser atribuída à hipersecreção, e o tratamento passou a ser feito com os bloqueadores H2. No final dos anos 1990, quando houve a descoberta de que a bactéria Helicobacter pylori seria o agente etiológico da úlcera péptica, o tratamento modificou-se mais uma vez para a atual tripla medicação.

Esse caráter de inconstância da evidência médica e sua natureza dinâmica constituem uma barreira para sua divulgação, seja para a sociedade ou para os profissionais da medicina. Tais contrariedades ocorrem porque a evidência é emergente e, por isso, é esperado que mude com o tempo, especialmente porque novas descobertas irão ocorrer ${ }^{32}$. Por outro lado, existem certos limites em relação à produção de evidências, impostos geralmente por questões éticas e econômicas, por exemplo. Posto que, se a evidência tem um caráter coletivo, sua produção, avaliação, interpretação, utilização e disseminação são processos sociais. Não obstante, persistem incertezas sobre quem tem autoridade para criar, interpretar e julgar a evidência por haver diferenças entre disciplinas na produção e no acesso ${ }^{32}$.

Por sua vez, as evidências científicas são fontes de informação utilizadas para apoiar as ações e os procedimentos na saúde, mas elas não são, por si mesmas, soluções ${ }^{33}$, assim como também não são conclusões. A opinião do especialista, por exemplo, é mais do que apenas evidência; ela é a combinação dos fatos, a interpretação que ele faz deles e a conclusão a que chega, levando em conta a evidência científica que o informa. ${ }^{33}$. Ademais, nem toda evidência tem o mesmo poder de convencimento, a evidência proveniente 
de resultados de pesquisas bem desenhadas e relatadas tem mais poder que observações casuais ou de pesquisas com falhas metodológicas. Há, ainda, que se considerar a qualidade da evidência e, para isso, é necessário estabelecer critérios sistemáticos de avaliação assim como a viabilidade de sua aplicação. Às vezes, a melhor evidência não é diretamente relevante em um determinado contexto específico ${ }^{34}$, enquanto uma evidência local pode ser de fundamental importância ${ }^{33}$.

É fato que as evidências científicas podem existir por si só, mas somente farão sentido quando utilizadas, assimiladas e incorporadas no processo decisório. No entanto, no processo de TC, como se viu, não só as evidências científicas influenciam uma decisão, posto que diversos fatores intervêm no uso efetivo do produto científico.

Lomas ${ }^{35}$ afirma que a tomada de decisões baseadas em evidências não pode ser vista como uma extensão lógica e linear da ciência, mas como um processo social no qual as evidências, além de serem de diferentes fontes e categorias, também estão sujeitas às predileções pessoais, ao poder profissional e à política organizacional.

Dobbins e colaboradores ${ }^{36}$ chamaram a atenção para o modo como se dá o uso das evidências, que, a depender da instância decisória, poderia ocorrer a priori ou a posteriori. Alguns informantes da sua pesquisa declararam que consultaram as evidências de forma prévia ao processo decisório, enquanto em outros casos as decisões foram tomadas e, em seguida, buscou-se um respaldo nas evidências e no conhecimento cientifico para justificar as escolhas, ou seja, as evidências foram usadas para legitimar e sustentar posicionamentos ${ }^{37}$, o que foi denominado por Dickinson ${ }^{1}$ uso simbólico. Como se viu, o tomador de decisões está sujeito às influências do contexto, de modo que este deve sempre ser levado em conta. "A decisão não pode ser vista como um evento isolado, mas como um ato que acontece em um contínuo de ações, por um indivíduo, em um contexto determinado"38 (tradução nossa). Da mesma forma, os decisores interferem no processo com seus próprios valores, opiniões, atitudes, motivações e habilidades ${ }^{39}$.

Assim, para se entender o processo decisório, faz-se necessário um olhar multidisciplinar, que passa pela questão social, política e organizacional ${ }^{40}$. Dois componentes são fundamentais nesse processo: as evidências e o contexto ${ }^{41}$. Mas, antes, é necessário que haja um acordo do que se consideram evidências entre o grupo tomador de decisões. Preocupados com essas questões, Dobbins e colaboradores ${ }^{36}$ conduziram uma pesquisa, no Canadá, com o intuito de verificar o que diferentes tipos de responsáveis por tomadas de decisões, em diferentes instituições e desempenhando variados papéis, pensavam ser evidências no processo decisório. O grupo selecionado para a pesquisa estava envolvido com decisões relacionadas à prestação de serviços de saúde para a população. Os resultados indicaram que, em geral, a tomada de decisões baseada em evidências era vista como um processo com múltiplas fontes de informação, entre as quais estavam as evidências das pesquisas, que seriam consultadas para planejar, implementar ou alterar programas e serviços.

Sendo assim, Lomas e colaboradores ${ }^{42}$, a partir de uma revisão sistemática, buscaram identificar os fatores que contam como evidência para formulação de diretivas no sistema de saúde. No relatório final dessa revisão, os autores apresentaram uma análise extensa, cujas definições e conclusões ajudaram a entender o papel das evidências no processo decisório. Eles identificaram duas categorias de evidências: as coloquiais e as científicas.

As evidências coloquiais nada mais são que aquelas do conceito 'popular' de evidência, isto é, qualquer coisa que estabelece fatos ou razões para acreditar que ela seja verdadeira. Seu peso nas decisões é dado por sua relevância, ou seja, pelo valor que elas têm para as pessoas envolvidas no processo decisório ou para a cultura local. Por seu turno, as evidências científicas seriam o conhecimento explícito, sistemático, replicável e verificável, e foram divididas em evidências científicas livres de contexto (context-free) e evidências sensíveis ao contexto (context-sensitive) ${ }^{42}$.

Essas duas categorias de evidências científicas têm diferentes funcionalidades e, por vezes, ambas são necessárias ao processo decisório. A evidência livre de contexto apontaria o que funciona de modo geral, enquanto a evidência sensível ao contexto poderia elucidar como funciona em determinadas circunstâncias ${ }^{42}$, 
embora a influência do contexto deva ser questionada e certos limites devam ser estabelecidos, pois sem eles pode-se facilmente sair do domínio da ciência para entrar no domínio do coloquial.

As evidências livres de contexto são produzidas pela ciência como aquele conhecimento que não tem compromisso com sua aplicabilidade em circunstâncias específicas, como uma ideia, uma visão do ideal. Já as evidências sensíveis ao contexto assumem que elas têm pouca ou nenhuma importância para as decisões a não ser que sejam adaptadas às circunstâncias da sua futura aplicação. Em ambas, a ciência cria as evidências, mas o que conta como evidência pode ser derivado de processos muito diferentes. Para a visão context-free, as evidências são os resultados das revisões sistemáticas, metanálises e estudos clínicos, por exemplo, enquanto para criar evidências context-sensitives é necessário integrar as evidências contextfree a outro tipo de informação e conhecimento, tais como: atitudes públicas, preferências dos pacientes, capacidade administrativa, viabilidade econômica, localização geográfica e outros.

Para ilustrar, foram incluídas a seguir as Figuras 1 e 2 encontradas no estudo de Lomas e colaboradores ${ }^{42}$, que contempla o expressado pelo UK Government Policy Hub, para o qual o ingrediente básico da evidência é a informação e a qualidade da decisão política que, por sua vez, depende da qualidade da informação, que pode ser derivada de várias fontes: "[...] conhecimento do especialista, pesquisa local e internacional existente; dados estatísticos existentes, consultas às pessoas chave envolvidas (stakeholders); avaliação de políticas anteriores; nova pesquisa, se necessária; fontes secundárias, incluindo a internet. A evidência pode também incluir análise de resultado de consultorias; custeio das opções políticas e os resultados da modelagem econômica ou estatística ${ }^{42 "}$ (tradução nossa). A Figura 1 mostra as diversas dimensões dos contextos e os métodos mais usados para gerar evidências científicas.

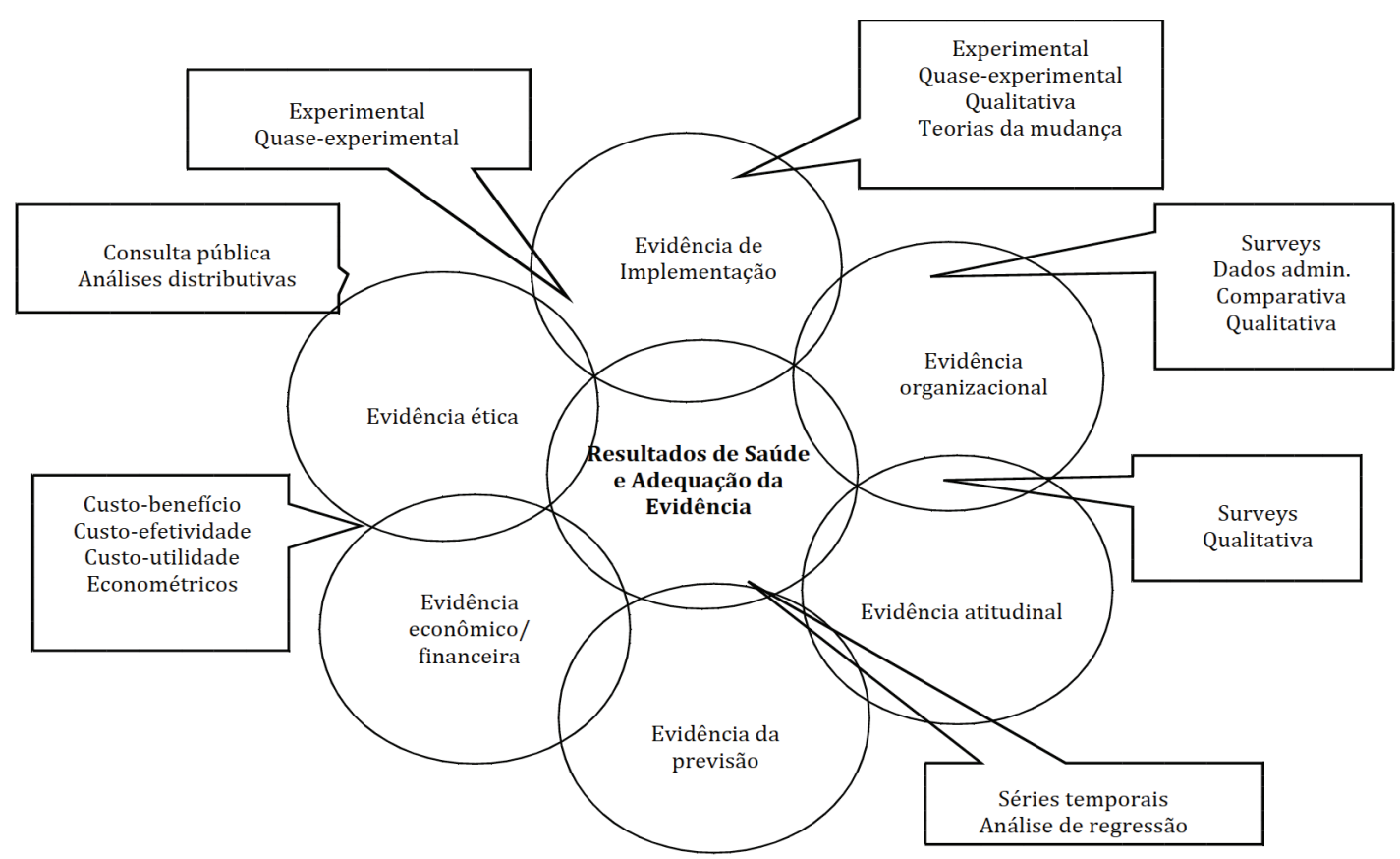

Figura 1 - Tipos de evidência científica (e seus métodos) para orientar o sistema de saúde sensível ao contexto Fonte: Adaptado e traduzido de Davies ${ }^{\text {vii }}$ apud Lomas et al. ${ }^{42}$. 


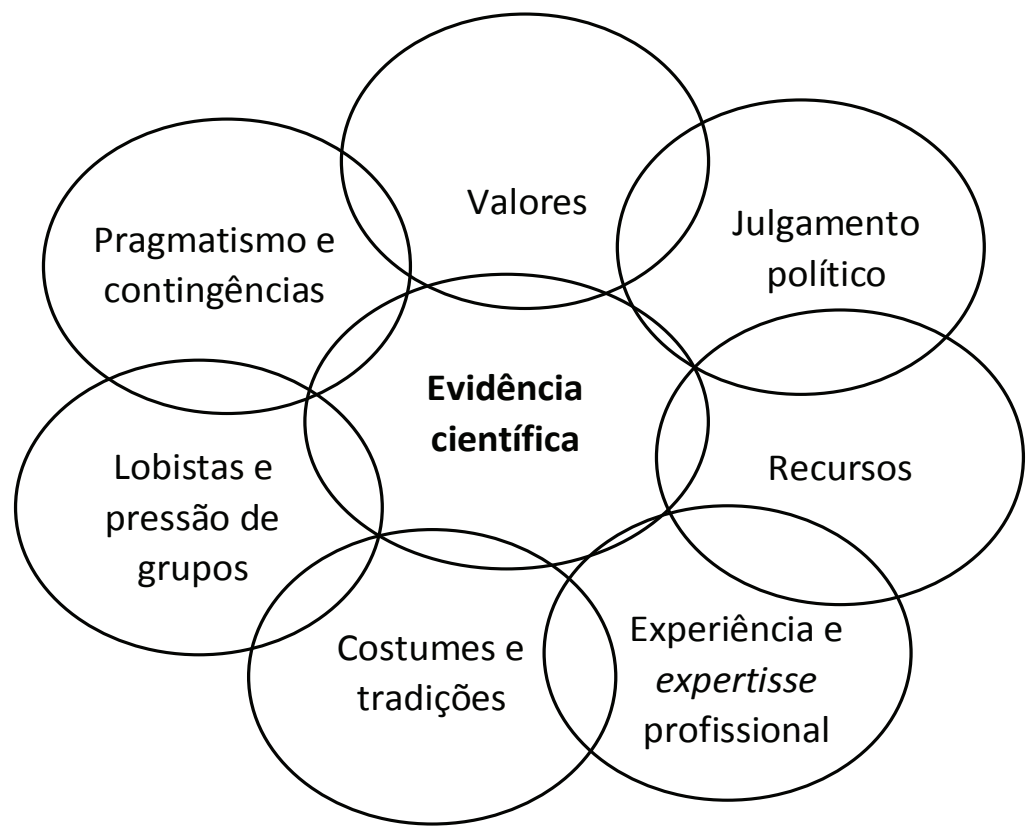

Figura 2 - Categorias de evidências coloquiais que podem complementar ou substituir as evidências científicas Fonte: Adaptado e traduzido de Davies ${ }^{\text {viii }}$ apud Lomas et al. ${ }^{42}$.

A integração de evidências de diferentes tipos e categorias não ocorre naturalmente, uma vez que têm origem e método diferentes e sua avaliação e utilização estarão baseadas, certamente, em parâmetros distintos. Lomas e colaboradores ${ }^{42}$ afirmam que a combinação das diferentes categorias e tipos de evidências é possível por meio de um processo deliberativo, no qual deve ocorrer a representatividade dos interesses de cada categoria de evidências. O que acontece no processo deliberativo, em lugar da tradicional política de cima para abaixo, é uma integração de pareceres e opiniões que contemplam a análise técnica, as pessoas chave (stakeholders) e o público leigo. O processo deliberativo, então, segundo Petts ${ }^{\mathrm{ix}}$ apud Lomas $^{42}$, é: "[...] um processo participativo que tem objetivos claros; é inclusivo e transparente; desafia a ciência; promove o diálogo entre as partes; promove o consenso sobre as decisões potenciais e tem impacto diretamente nelas" (tradução nossa).

Para melhor entender como as evidências das pesquisas podem chegar a influenciar o processo decisório, é necessário conhecer como se dá a participação dos pesquisadores nas instâncias políticas. Nutley, Walter e Davies ${ }^{4}$ estudaram essa relação e identificaram que há pelo menos três formas de abordagem relacionadas a essa questão: "a) Abordagem consensual - quando há um bom entendimento entre os que elaboram as políticas públicas e os pesquisadores a respeito do principal ponto em pauta e os caminhos para abordá-lo. [...]. [Os pesquisadores trabalham] com o objetivo de melhorar a eficácia das decisões e os resultados das atividades. [...]; b) Abordagem contenciosa - os pesquisadores se posicionam ao lado dos decisores; nem sempre contribuem diretamente para o processo, porém mantêm uma instância crítica em relação ao governo, à sociedade e às instituições. $O$ papel dos pesquisadores é atuar como 'críticos morais' [...]; c) Abordagem do paradigma desafiador - os pesquisadores mais radicais atuam fora do paradigma prevalente, usando seu trabalho para problematizar as estruturas estabelecidas e as formas de pensar. Propõem novos princípios para a ação, esperando obter apoio político para levá-los em frente" (tradução nossa).

Essas constatações deixam claro como o ambiente é difícil e pouco propício para o processo de TC, com exceção da abordagem consensual. Mas não é apenas a relação que é fundamental, também importa

\footnotetext{
viii Op. cit.

ix Petts J. Barriers to participation and deliberation in risk decisions: evidence from waste management. J Risk Res 2004;7(2):115-33.
} 
conhecer quais são as necessidades de informação dos envolvidos no processo decisório e como deve ser o produto da ciência para surtir um melhor efeito.

Com intuito de entender quais são as necessidades de informação científica dos envolvidos no processo decisório, Dobbins e colaboradores ${ }^{43}$ realizaram uma pesquisa em três diferentes instituições canadenses comprometidas com questões relacionadas às crianças com necessidades especiais. Os seus resultados indicaram que os prestadores de serviços, os administradores e os que tomam as decisões têm preferências pelas evidências de fácil acesso e de alta qualidade passíveis de serem obtidas de maneira rápida. Necessitam de informação sintetizada, pontuando as implicações dos achados para a prática e para as políticas. Nesse estudo, além de mapear as necessidades e preferências pelas evidências, os autores puderam constatar a complexidade do processo de translação do conhecimento que vai além de simplesmente "oferecer a informação certa à pessoa certa no momento certo" 43 .

Uma vez que o processo deliberativo compreende também o julgamento e a avalição da evidência, ponderando as consequências desejáveis e indesejáveis da escolha de uma determinada opção ${ }^{44}$, algumas características se tornam indispensáveis para que ocorra sua utilização. Para que as evidências possam satisfazer essas necessidades e ter um papel determinante nas decisões voltadas para a saúde foram apontadas as seguintes condicionantes: disponibilidade, acessibilidade, validade, oportunidade, comunicabilidade e serem manipuláveis ${ }^{39}$.

\section{Entraves para a translação do conhecimento}

Como foi visto, a TC envolve a participação ativa e a colaboração entre os interessados no desenvolvimento de métodos para comunicar o conhecimento e para articular perguntas de pesquisa ${ }^{20}$. Essa colaboração deveria se dar basicamente entre os cientistas e os que tomam decisões e elaboram as políticas públicas.

Dias e outros ${ }^{10}$ afirmam que, apesar do consenso quanto à validade das evidências científicas para o desenvolvimento de políticas públicas de saúde, o seu uso de forma sistemática é simplesmente incipiente. Um dos entraves seria a escassa comunicação e colaboração entre pesquisadores e os que tomam as decisões. "O diálogo entre a gestão e a academia tem origem nas diferenças das atividades, dos interesses e da forma de inserção dos profissionais nos processos relacionados à formulação, implementação e avaliação de políticas públicas de saúde" ${ }^{\text {”o }}$.

Os países latino-americanos, por sua vez, têm se destacado por serem os mais deficientes quanto à divulgação de evidências de pesquisa em saúde, assim como também produzem muito poucos estudos que visem promover uma discussão sobre políticas informadas por evidências científicas e $\mathrm{TC}^{10}$.

Pearson, Jordan e Munn ${ }^{45}$ identificam pelo menos três problemas no processo de TC: 1) a distância entre a necessidade de conhecimento dos pacientes, dos profissionais de saúde, dos governos e das instituições e o trabalho que fazem os cientistas e pesquisadores; 2) a distância entre a pesquisa teórica, epidemiológica e de laboratório e a pesquisa clínica; e 3) a distância entre a aplicação clínica dos resultados da pesquisa e a adoção de condutas, ações e políticas de saúde.

Almeida e Báscolo ${ }^{27}$ chamam a atenção para o fato de que a formulação, implementação e avaliação de políticas públicas são atividades influenciadas pelos valores dos atores envolvidos e pela realidade social na qual estão imersos, em todos os níveis do processo burocrático. As escolhas são fortemente marcadas pelos contextos político, econômico e institucional, e as opções também são delimitadas por esses contextos.

Da mesma maneira, outros autores veem os entraves, para adotar decisões embasadas na ciência, no ambiente político. Muitas vezes, é simplesmente impossível estabelecer decisões de acordo com as evidências em situações de mobilização da sociedade, por exemplo, ou perante o veto nas instâncias superiores e a influência dos interesses econômicos, ideológicos, político-partidários e da sociedade como um todo ${ }^{23,46}$. Bensing ${ }^{2}$ anota os marcantes conflitos de interesse entre decisores políticos e pesquisadores sobre os tópicos de pesquisa e sua forma de abordá-los da seguinte forma: “[...] problemas complexos versus simplificação do 
problema; soluções focadas versus interesse em detalhes relacionados, porém separadamente; redução de incertezas versus encontrar a verdade; pressa versus tempo para pensar; controle e demora versus publicar ou perecer; manipulação versus explanação; soluções viáveis e pragmáticas versus deliberações aprofundadas” (tradução nossa).

$\mathrm{Na}$ área de saúde, Haines Kuruvilla e Borchert47 identificaram as barreiras potenciais à TC em sete diferentes ambientes: “[...] sistema de saúde (falta de recursos financeiros, incentivos financeiros inapropriados; recursos humanos inadequados em quantidade e qualidade etc.); ambiente de prática (limitações de tempo; falta de organização dos registros etc.); ambiente educacional (currículo escolar falho; educação continuada inapropriada ou inexistente; falta de incentivo para participar de atividades educacionais etc.); ambiente social (influência da mídia criando demandas ou crenças inapropriadas, modismos e tendências; desvantagens de acesso e de competência informacional; e comportamentos de saúde); ambiente político (ideologia inconsistente com evidências; corrupção; pensamento de curto-prazo); profissional médico (conhecimento obsoleto; influência da opinião de especialistas importantes; crenças e atitudes); pacientes (demanda de cuidados ineficazes; percepções e crenças culturais sobre o cuidado)" (tradução nossa).

Uma outra característica que envolve esse processo, dificultando-o, é o fato de que as evidências não são facilmente acessíveis aos responsáveis pelas tomadas de decisão; eles carecem de tempo para buscar, avaliar e aplicar os resultados das pesquisas, o que torna impossível disporem de um estoque de evidências suficientes ${ }^{4}$. Outras barreiras para o uso das evidências da pesquisa apontadas por Dobbins e colaboradores $^{43}$ são: falta de acesso à pesquisa atualizada, habilidades limitadas de avaliação crítica por parte dos decisores, excessiva quantidade de revisões, ambiente de trabalho que não facilita a transferência de pesquisa e apropriação, falta de autoridade na tomada de decisões para implementar os resultados, processo decisório que não facilita a translação de pesquisa e apropriação, resistência à mudança e recursos limitados de implementação.

\section{Estratégias para implementar a translação do conhecimento}

A preocupação mundial de contribuir para um efetivo aproveitamento da pesquisa nas decisões de saúde pode se traduzir no documento do Global Fórum for Health Research em conjunto com a OMS ${ }^{48}$, elaborado com o intuito de melhorar a forma de produzir políticas de saúde baseadas em evidências. O guia elenca seis indicações de como melhorar um sistema de saúde, especialmente em países pobres ou em desenvolvimento. As recomendações deixam clara a necessidade de uma maior interação ciênciagoverno. São elas:

a) que os que elaboram as políticas demandem de forma proativa a produção de evidências dos grupos de pesquisa;

b) que se crie uma instância de diálogo na qual os políticos possam discutir com os cientistas;

c) que se incremente a coleção de sínteses e apresentação de evidências para que seja de fácil uso pelos políticos;

d) que se melhore a capacidade técnica dos políticos para acessar, entender e utilizar a evidência;

e) que se deem incentivos para que os pesquisadores se envolvam no processo decisório de modo que suas opiniões e experiências possam ser usadas na prática;

f) que se desenvolvam redes entre a comunidade de políticos e pesquisadores para transmitir as evidências e desenvolver relações de trabalho de confiança.

Tais ações estratégicas devem ainda ser complementadas com atitudes pontuais por parte da ciência. Lavis e colaboradores ${ }^{49}$, com o intuito de estabelecer como as organizações de pesquisa em saúde podem efetivamente transferir conhecimentos para os responsáveis pelas tomadas de decisão, apresentaram um modelo que foca cinco fatores a serem levados em consideração na comunicação dos resultados de 
pesquisa: a) o que deve ser transferido - a mensagem; b) para quem deve ser transferido o conhecimento - o público-alvo; c) por quem deve ser feita essa transferência de conhecimento - o mensageiro; d) como deve ser transferido esse conhecimento - o processo de translação do conhecimento e a infraestrutura de comunicação que o sustenta; e) com que efeito deve ser transferido o conhecimento - avaliação. Os elementos que compõem esse quadro variam de acordo com os públicos, que podem ser os seguintes: público geral/receptores de serviços (cidadãos, pacientes e clientes); prestadores de serviços (médicos e demais profissionais de saúde); decisores gerenciais (gestores hospitalares, organizações da sociedade, negócios particulares); aqueles que tomam decisões políticas no âmbito federal, estadual, municipal ou local.

Com relação às dificuldades enfrentadas pelos que tomam decisão sobre o uso do conhecimento científico e os problemas antes descritos da falta de interação entre os atores necessários à TC, Dias e colaboradores ${ }^{10}$ afirmam que são necessárias estratégias de tradução e de disseminação do conhecimento. Ao serem elaborados, estes produtos devem levar em conta os diferentes contextos institucionais e sociais.

Em muitos aspectos, os estudos secundários, especificamente revisões sistemáticas e metanálises, têm sido eficientes para uma melhor efetivação do processo de $\mathrm{TC}^{49,50}$. Não só pela produção de evidências de alto valor, mas também porque, devido à frequente insuficiência de estudos individuais, elas servem para apontar as lacunas de informação e em que esfera é necessário um maior investimento em pesquisa ${ }^{17}$.

Porém, as revisões sistemáticas, por si só, apesar de reunirem e avaliarem os resultados de diversos estudos, não garantem a efetivação do uso, pois elas são um material bastante complexo para as pessoas leigas. Assim, surgiram, no cenário, as sínteses, sinopses e sumários de evidências que servem para informar aos decisores, e foram também implementados sistemas de apoio à decisão interligados com registros de informação e bases de dados. São exemplos destas tecnologias o ACCESSSS Federated Search da McMaster University do Canadá, a TRIP Medical Database, BMJ Best Practice, Health Evidence, Health System Evidence, Epistemonikos, DynaMed Plus, BMJ Evidence-Based Medicne, Essential Evidence Plus e o UpToDate, Base Regional de Informes de Avaliação de Tecnologias em Saúde das Américas (BRISA) e, no Brasil, o Portal de Saúde Baseada em Evidências do Ministério da Saúde.

Outro aspecto que ressaltam Dobbins e colaboradores ${ }^{36}$ é o papel das instituições produtoras de pesquisa, que devem estar atentas para as questões que precisam de resposta, mas, também, que tipo de respostas são úteis às decisões que têm de ser tomadas. Dessa forma, o investimento das instituições de pesquisa deveria estar orientado para identificar o público-alvo e estabelecer relações de colaboração, de modo a desenvolver em conjunto perguntas de pesquisa, assim como os desenhos mais apropriados para obtê-las, e, finalmente, trabalhar em conjunto para a interpretação e aplicação dos resultados nas políticas e decisões de saúde.

Integrar o usuário do conhecimento no processo de TC é outra estratégia que pode facilitar e melhorar os resultados. Os usuários do conhecimento podem participar das diversas etapas, desde o início ajudando a identificar o problema da pesquisa, contribuindo com informações acerca do contexto e da melhor maneira de abordar os sujeitos da pesquisa, ou dando ideias de como implementar a coleta de dados, uma vez que possuem informações às quais os pesquisadores não têm acesso. São também atores fundamentais para propiciar a utilização dos resultados, assinalando os canais e as pessoas chave que podem intermediar a disseminação do conhecimento ${ }^{13}$.

Algumas ações concretas têm sido implementadas por diversas instituições para propiciar a TC. Dentre elas, a criação dos instrumentos Knowledge Translation Planing Template ${ }^{51}$ e o Guide to Knowledge Translation Planning ${ }^{52}$ para desenvolver um plano de TC. Assim como também têm sido instituídos centros específicos para realização de pesquisas relacionadas à TC, produção de material especializado, promoção de atividades e disseminação do conhecimento. Um exemplo é o programa Translating Research Into Practice (TRIP) da Agency for Healthcare Research and Quality, cujo objetivo é gerar novos conhecimentos sobre as abordagens que promovam a utilização rigorosa de evidências para melhorar os cuidados destinados ao paciente. O propósito dessa Agência é aumentar a utilização dos resultados da pesquisa, das ferramentas 
e da informação científica que funciona em diversos cenários de prática e entre diversas populações. Esses exemplos, tanto das tecnologias como dos centros específicos de geração de evidências encontram representatividade, no Brasil, no trabalho da Rede Brasileira de Avaliação de Tecnologias em Saúde (Rebrats) e no braço brasileiro da Rede para Políticas Informadas por Evidências (EVIPNet) coordenada pelo Departamento de Ciência e Tecnologia da Secretaria de Ciência, Tecnologia e Insumos Estratégicos do Ministério da Saúde. Essas duas redes promovem o uso de evidências científicas para o desenvolvimento e implementação das políticas de saúde.

\section{Considerações finais}

A translação do conhecimento na área de saúde é entendida de diversas formas a depender do lugar específico em que se situe o problema. A pesquisa translacional na área médica difere do conceito de TC. Porém, alguns autores entendem que TC é um processo dividido em partes, cujo objetivo é promover e efetivar o uso da pesquisa, é deslocar o conhecimento científico do seu habitat natural, academia e centros de pesquisa, para a prática e para as políticas de saúde. Na área de saúde, o processo de TC é especialmente complexo porque o contexto de cada decisão é sempre peculiar, tem suas características próprias, e cada uma dessas particularidades importa na decisão, e não apenas a evidência científica. Por isso, é necessário avaliar o contexto antes de implementar iniciativas de TC, para que haja um ajuste entre a teoria e a realidade, sendo isto fundamental para o sucesso.

Os modelos analisados mostraram que os domínios da ciência e da prática podem estar em campos diferentes do fazer e do pensar, mas as mudanças que vêm ocorrendo, no sentido de uma aproximação para a qual há de se focar na informação e na comunicação, propiciam um ajuste que permite facilitar o uso e a translação do conhecimento. Assim, a mudança mais profunda está nas formas e ambientes de produção do conhecimento, onde se destacam o ambiente da prática e as redes de instituições e organizações.

A leitura realizada também mostrou que, no processo deliberativo, deve-se persistir para alcançar uma participação equânime de todas evidências relevantes e de diferentes origens, respeitando a integridade científica, levando em conta a capacidade de implementação das descobertas, junto à responsabilidade de expertos em avaliações da qualidade das evidências e o envolvimento daqueles que se verão afetados por tais decisões.

Mas, para que esse processo ocorra, alguns desafios precisam ser enfrentados, os quais Cabieses e Espinoza $^{53}$ resumiram de forma muito clara em cinco tópicos que utilizamos para encerrar este artigo e o estudo que o fundamenta: “1) É preciso entender que a evidência gerada pela pesquisa é apenas um componente a mais para a tomada de decisões [...]; 2) A entrada da evidência científica em saúde como pauta na elaboração de políticas sanitáriasdependedequeas autoridadesabramespaçosparasuaconsideração,espaçosquenemsempreestãodisponíveis no nível político; 3) As comunidades de pesquisa e da política têm uma compreensão diferente sobre o significado de "evidência”, eistoprecisaserdiscutidodemodoasechegaraum consensoparasuainclusãofuturanatomada dedecisões; 4) A pesquisa e a política operam em distintos prazos de tempo. As decisões políticas podem ser tomadas em semanas ou dias, enquanto a pesquisa requer meses ou anos para gerar evidência científica; 5) A pesquisa em saúde se concentra, principalmente, em processos causais, enquanto a política se orienta preferencialmente para conhecer aquilo que "funciona" (e não necessariamente para revelar "que" é ou o que a faz funcionar)" (tradução nossa). 


\section{Referências}

1. Dickinson HD. A sociological perspective on the transfer and utilization of social scientific knowledge for policy-making. In: Limieux-Charles L, Champagne F, editors. Using knowledge and evidence in health care: multidisciplinary perspectives. Toronto: University of Toronto; 2004. p. 41-69.

2. Bensing JM, Dekker J, Delnoij DMJ, Groenewegen PP. Doing the right thing and doing it right: toward a framework for assessing the policy relevance of health services research. Int J Technol Assess Health Care. 2003;19(4):604-12.

3. Limieux-Charles L, Champagne F. Using knowledge and evidence in health care: multidisciplinary perspectives. Toronto: University of Toronto; 2004.

4. Nutley SM, Walter I, Davies HTO. Using evidence: how research can inform public services. Bristol, UK: University of Bristol; 2007.

5. National Library of Medicine (US). Medical subject headings [Internet]. Betesda: NLM; 2018 [cited 2018 Dec 20]. Available from: https://www.nlm.nih.gov/mesh/meshhome.html.

6. Biblioteca Virtual em Saúde. Descritores em ciências da saúde [Internet]. São Paulo: Bireme; 2017 [citado em 2019 dez. 20]. Disponível em: http://decs.bvs.br/.

7. Silva OC, Cardoso NM. Translational investigation: it essence, opportunity and merit. Medicina (Ribeirão Preto). 2012;45(4):409-10.

8. Tsukumo DM, Carvalho BM, Carvalho Filho MA, Saad MJ. Translational research into gut microbiota: new horizons on obesity treatment: updated 2014. Arch Endocrinol Metab. 2015;59(2):154-60. doi:10.1590/2359-3997000000029.

9. Bampi VF, Gomes CF, Olivera LBd, Steffen N. Medicina translacional. Acta méd (Porto Alegre). 2010;31:165-72.

10. Dias RISC, Barreto JOM, Vanni T, Candido AMSC, Moraes LH, Gomes MAR. Estratégias para estimular o uso de evidências científicas na tomada de decisão. Cad Saúde Colet. 2015;23(3):316-22.

11. Guimarães MCS. Uma geografia para a ciência faz diferença: um apelo da Saúde Pública. Cad Saúde Pública. 2010;26(1):50-8.

12. Guimarães R. Pesquisa translacional: uma interpretação. Ciênc Saúde Colet. 2013;18(6):1731-44.

13. Oelke ND, Lima MADdS, Acosta AM. Knowledge translation: translating research into policy and practice. Rev Gaucha Enferm. 2015;36(3):113-7.

14. Padilha MI. Pesquisa translacional: qual a importância para a prática da enfermagem? Texto Context Enferm. 2011;20(3):219-24.

15. Silva $A B$, Morel $C M$, Moraes IHSd. Proposta conceitual de telessaúde no modelo da pesquisa translacional. Rev Saude Publica. 2014;48(2):347-56.

16. McKibbon KA, Lokker C, Wilczynski NL, Ciliska D, Dobbins M, Davis DA et al. A cross-sectional study of the number and frequency of terms used to refer to knowledge translation in a body of health literature in 2006: a Tower of Babel? Implement Sci. 2010;5:16. doi:10.1186/1748-5908-5-16.

17. Grimshaw JM, Eccles MP, Lavis JN, Hill J, Squires JE. Knowledge translation of research findings. Implement Sci. 2012;7(50):1-17.

18. Estabrooks CA, Thompson DS, Lovely JJ, Hofmeyer A. A guide to knowledge translation theory. J Contin Educ Health Prof. 2006;26(1):25-36. doi:10.1002/chp.48.

19. Sung NS, Crowley WF, Jr., Genel M, Salber P, Sandy L, Sherwood LM et al. Central challenges facing the national clinical research enterprise. Jama. 2003;289(10):1278-87.

20. Côrtes CT, Santos RCSd, Caroci AdS, Oliveira SG, Oliveira SMJVd, Riesco MLG. Implementation methodology of practices based on scientific evidence for assistance in natural delivery: a pilot study. Rev Esc Enferm USP. 2015;49(5):716-25.

21. Canadian Institutes of Health Research. About knowledge translation. 2013 [cited 2018 Dec 20 ]. p. 1. Available from: http://www.cihr-irsc.gc.ca/e/29418.html. 
22. Graham ID, Logan J, Harrison MB, Straus SE, Tetroe J, Caswell W et al. Lost in knowledge translation: time for a map? J Contin Educ Health Prof. 2006;26(1):13-24. doi:10.1002/chp.47.

23. World Health Organization. World health report for better health: strengthening health systems. Geneva: WHO; 2004.

24. National Center for the Dissemination of Disability Research. What is knowledge translation? Focus Technical Brief. 2005(10):1-4.

25. Greenhalgh T, Robert G, Macfarlane F, Bate P, Kyriakidou O. Diffusion of innovations in service organizations: systematic review and recommendations. Milbank Q. 2004;82(4):581-629. doi:10.1111/ j.0887-378X.2004.00325.x

26. Denis JL, Lehoux $\mathrm{P}, \mathrm{Champagne} \mathrm{F}$. A knowledge utilization perspective on fine-tuning dissemination and contextualizing knowledge. In: Limieux-Charles L, Champagne F, editors. Using knowledge and evidence in health care: multidisciplinary perspectives. Toronto: University of Toronto; 2004. p. 28-40.

27. Almeida C, Bascolo E. Use of research results in policy decision-making, formulation, and implementation: a review of the literature. Cad Saúde Pública. 2006; 22 Suppl:S7-19; discussion S20-33.

28. Audi R. The Cambridge dictionary of philosophy. 2. ed. Cambridge: Cambridge University; 1999.

29. DiFate V. Evidence. The Internet Encyclopedia of Philosophy [Internet]. 2015 [cited 2018 Dec. 20]. Available from: http://www.iep.utm.edu/evidence/.

30. Prewitt K, Schwandt TA, Straf ML. Using science as evidence in public policy. Washington, D.C.: National Research Council; 2012.

31. Rycroft-Malone J, Stetle CB. Commentary on evidence, research, knowledge: a call for conceptual clarity. Worldviews Evidence-Based Nurs. 2004;1(2):98-101.

32. Upshur REG. Seven characteristics of medical evidence. J Evaluat Clin Pract. 2000;6(2):93-7.

33. Oxman AD, Lavis JN, Lewin S, Fretheim A. Support tools for evidence-informed health Policymaking (STP) I: what is evidence-informed policymaking? Health Res Policy Syst. 2009;7(Suppl 1):51. doi:10.1186/1478.

34. Galvao MC, Ricarte IL, Grad RM, Pluye P. The Clinical Relevance of Information Index (CRII): assessing the relevance of health information to the clinical practice. Health Info Libr J. 2013;30(2):110-20. doi:10.1111/hir.12021.

35. Lomas J. Understanding evidence-based decisions-making: or why keyboards are irrational. In: LemieuxCharles L, Champagne F, editors. Using knowledge and evidence in health care: multidisciplinary perspectives. Toronto: University of Toronto; 2004. p. 281-90.

36. Dobbins $\mathrm{M}$, Jack $\mathrm{S}$, Thomas $\mathrm{H}$, Kothari A. Public health decision-makers' informational needs and preferences for receiving research evidence. Worldviews Evidence-Based Nurs. 2007;4(3):156-63.

37. Innvaer S, Vist G, Trommald M, Oxman A. Health policy-makers' perceptions of their use of evidence: a systematic review. J Health Serv Res Policy]. 2002;7(4):239-44. doi:10.1258/135581902320432778.

38. Grant A, Kushniruk A, Villeneuve A, Boldoc N, Moshyk A. An informatic perspective on decision support and the process of decision-making in health care. In: Limieux-Charles L, Champagne F, editors. Using knowledge and evidence in health care: multidisciplinary perspectives. Toronto: University of Toronto; 2004. p. $199-226$

39. Champagne F, Limieux-Charles L, McGuire W. Towards a broader understanding of the use of knowledge and evidence in health care. In: Limieux-Charles L, Champagne F, editors. Using knowledge and evidence in health care: multidisciplinary perspectives. Toronto: University of Toronto; 2004. p. 3-17.

40. Limieux-Charles L, Barnsley J. An innovation diffusion perspective on knowledge and evidence in health care. In: Limieux-Charles L, Champagne F, editors. Using knowledge and evidence in health care: multidisciplinary perspectives. Toronto: University of Toronto; 2004. p. 115-38.

41. Dobrow MJ, Goel V, Upshur REG. Evidence-based health policy: context and utilisation. Social Sci Med. 2004;58(1):207-17. doi: 10.1016/s0277-9536(03)00166-7.

42. Lomas J, Culyer T, McCutcheon C, McAuley L, Law S, Foundation CRC. Conceptualizing and combining evidence for health system guidance: final report. Ottawa: Canadian Health Service Research Foundation; 2005. p. 12 
43. Dobbins $M$, Rosenbaum $P$, Plews $N$, Law M, Fysh A. Information transfer: what do decision makers want and need from researchers? Implement Sci. 2007;2:20. doi:10.1186/1748-5908-2-20.

44. Oxman $A D$, Lavis JN, Fretheim A. Use of evidence in WHO recommendations. Lancet. 2007;369(9576):1883-9. doi:10.1016/s0140-6736(07)60675-8.

45. Pearson A, Jordan Z, Munn Z. Translational science and evidence-based healthcare: a clarification and reconceptualization of how knowledge is generated and used in healthcare. Nurs Res Pract. 2012;2012:792519. doi:10.1155/2012/792519.

46. Lavis JN, Ross SE, Hurley JE, Hohenadel JM, Stoddart GL, Woodward CA, et al. Examining the role of health services research in public policymaking. Milbank Q. 2002;80(1):125-54.

47. Haines A, Kuruvilla S, Borchert M. Bridging the implementation gap between knowledge and action for health. Bull World Health Organ. 200482(10):724-32.

48. Global Forum for Health Research; World Health Organization. The use of evidence in policy-making for health [Internet]. 2013 [cited 2018 Dec 20]. Available from: www.globalforumhealth.org.

49. Lavis JN, Robertson D, Woodside JM, McLeod CB, Abelson J, Group KTS. How can research organizations more effectively transfer research knowledge to decision makers? Milbank Q. 2003;81(2):221-48.

50. Moat KA, Lavis JN, Wilson MG, Rottingen JA, Barnighausen T. Twelve myths about systematic reviews for health system policymaking rebutted. J Health Serv Res Policy. 2013;18(1):44-50. doi 10.1258/ jhsrp.2012.011175.

51. Barwick M. Knowledge translation planning template. Ontario: The Hospital for Sick Children; 2013.

52. Canadian Institutes of Health Research. Guide to knowledge translation planning at CIHR: integrated and end-of-grant approaches [Internet]. 2016 [cited 2018 Dec 20]. Available from: http://www.cihr-irsc. gc.ca/e/45321.html.

53. Cabieses B, Espinoza MA. La investigación translacional y su aporte para la toma de decisiones en políticas de salud. Rev Peruana Med Exp Salud Pública. 2011; 28(2):288-97. 